\title{
Conservative Drill less Restoration of Teeth: A New Dimension-Air Abrasion
}

\author{
Shruti Malik* \\ Radix Cosmo Dental, India \\ *Corresponding author: Shruti Malik, CEO, Radix Cosmo Dental, Delhi, India
}

Submission: 眥 December 07, 2017; Published: 眥 February 16, 2018

\begin{abstract}
Air Abrasion is a drill-less technique used by dentists in order to remove tooth decay or dental enamel from teeth. Air Abrasion Dentistry has evolved over a period of time as an alternative means of conservative cavity protection. This article reviews the development of Dental Air Abrasion, its uses, how it works, its safety uses and the advantages as well as disadvantages of this techniques.
\end{abstract}

Keywords: Air abrasion; Conservative cavity protection; Less traumatic alternative; Minimal invasive technique

\section{Introduction}

This kind of Dentistry is the need of the hour as the already existing techniques are being challenged and new conservative techniques need to be recommended. Air Abrasion Dentistry was introduced in the 1950s as an alternative to the needle and dry cavity protection by Dr. Robert Black.

Air Abrasion System is a conservative and a less traumatic alternative to the high-speed drill techniques. It allows the doctor to selectively remove decay, leaving healthier tooth structure. It can help the dentist to find hidden decay.

Air Abrasion has proved to be the most convenient way than the already existing techniques. It works in a very efficient manner as it removes the tooth decay in a very gentle way. This technique has proved to be a pleasant experience for the ones who fear dentistry since their birth. Such efficient techniques have now changed the entire procedure of Dentistry [1-3].

\section{How does it Work?}

During Air Abrasion, an instrument is used that works like a mini sandblaster to spray away the decay. Also, some fine particles are used to stain away the decayed portion of the teeth. These particles are made up of silica, aluminium oxide or baking soda which are impelled inside the tooth through a compressed gas by a dental handpiece. With the removal of tooth decay, these particles are removed from the teeth.

A number of parameters such as air pressure, particle size, the quantity of particles passing through a nozzle, nozzle diameter of the handpiece, angulation of nozzle of the handpiece, distance from the object, and time of exposure to the object vary the quantity of tooth removal and depth of penetration [4-6].

\section{Advantages of Air Abrasion}

As compared to the traditional drilling method, there are various advantages of air abrasion dentistry. The advantages of Air Abrasion Dentistry include:

a. It produces no heat, pressure or vibration.

b. It sometimes reduces the need for anaesthesia.

c. It leaves more healthy teeth tissues behind.

d. It also reduces the risk of fracturing the tooth and thereby affecting the lifespan of the filling done.

e. This technique is much simpler than the traditional drilling techniques.

\section{Disadvantages of Air Abrasion}

Every medical technique does carry some disadvantages with it and same is with Air Abrasion technique. Its disadvantages include:

a) The particles used during air abrasion are sensitive and can't necessarily be free of pain.

b) Air Abrasion is best suited for small cavities but not for those which are close to the tooth's pulp.

c) It cannot be used to remove hard enamels.

d) It cannot be used in conjunction with magnification devices such as loupes or dental operating microscopes as the particles used can cause damage to the lenses.

e) Crowns, onlays, and inlays cannot be prepared using air abrasion. 


\section{Applications of Air Abrasion}

So, knowing of air abrasion as only for removing cavities and tooth decay is not enough. It is also used in various other teeth related problems such as:

I. Removal of old composite restorations.

II. Preparation of tooth surface for bonding or sealants.

III. Removal of stains and tooth discolorations.

IV. Recovering the cracks in the tooth.

V. Removal of pit and fissure surface stain on enamel.

\section{Conclusion}

Dental Air Abrasion is, therefore, a revival to the new restorative technology and has given a new dimension to the "Minimal Invasive Technology". This new bonding with the tooth structure through effective techniques has helped to provide the patients with conservative dentistry. Apart from providing preventive measures to the patient, the dentist can now make them familiar with the

Creative Commons Attribution 4.0

International License

For possible submission use the below is the URL Submit Article benefits of preventive dental care by educating them to such effective and gentle techniques.

\section{References}

1. Rainey J (2002) Air abrasion: An emerging standard of care in conservative operative dentistry. Dent Clin North Am 46(2): 185-209.

2. Eakle WS, Wong J, Huang H (1995) Micro leakage with micro abrasion versus acid etched enamel and dentin (abstract 160). J Dent Res 74: 31.

3. Adachi JA, von Fraunhofer JA, Barnes DM (1999) Effect of cavity preparation of composite restoration micro leakage behaviour (abstract 3042). J Dent Res 78: 486

4. Gray GB, Carey GPD, Jagger DC (2006) An in vitro investigation of a comparison of bond strengths of composite to etched and air-abraded human enamel surfaces. J Prosthod 15(1): 2-8.

5. Borsatto MC, Catirse AB, Palma Dibb RG, Nascimento TN, Rocha RA, et al. (2002) Shear bond strength of enamel surface treated with air-abrasive system. Braz Dent J 13(3): 175-178.

6. Sinhori BS, Caldeira de Andrada MA, Lopes GC, Junior SM, Baratieri LN (2017) Influence of teeth preparation finishing on the adaptation of lithium discilste crowns. International Journal of Biomaterials 2017(2017): 1-6.

\section{Your subsequent submission with Crimson Publishers will attain the below benefits}

- High-level peer review and editorial services

- Freely accessible online immediately upon publication

- Authors retain the copyright to their work

- Licensing it under a Creative Commons license

- Visibility through different online platforms

- Global attainment for your research

- Article availability in different formats (Pdf, E-pub, Full Text)

- Endless customer service

- Reasonable Membership services

- Reprints availability upon request

- One step article tracking system 